\title{
The Positive Psychology Virtues in the New Palestinian Textbooks
}

\author{
Fakher Khalili, $^{1, *}$, Saida Affouneh ${ }^{2}$, Ashraf Sayegh ${ }^{2}$, Ali Zuhdi Shaqour ${ }^{2}$, Muna Shaath ${ }^{1}$ \\ ${ }^{1}$ Department of Psychology and Counselling, AN-Najah National University, Nablus, West Bank, Palestine \\ ${ }^{2}$ Department of Curriculum and Teaching Methods, AN-Najah National University, Nablus, West Bank, Palestine
}

Received October 7, 2020; Revised December 7, 2020; Accepted December 18, 2020

\section{Cite This Paper in the following Citation Styles}

(a): [1] Fakher Khalili, Saida Affouneh, Ashraf Sayegh, Ali Zuhdi Shaqour, Muna Shaath, "The Positive Psychology Virtues in the New Palestinian Textbooks," Universal Journal of Educational Research, Vol. 8, No. 12B, pp. 8351-8361, 2020. DOI: 10.13189/ujer.2020.082640.

(b): Fakher Khalili, Saida Affouneh, Ashraf Sayegh, Ali Zuhdi Shaqour, Muna Shaath (2020). The Positive Psychology Virtues in the New Palestinian Textbooks. Universal Journal of Educational Research, 8(12B), 8351-8361. DOI: 10.13189/ujer.2020.082640.

Copyright $\subseteq 2020$ by authors, all rights reserved. Authors agree that this article remains permanently open access under the terms of the Creative Commons Attribution License 4.0 International License

\begin{abstract}
The purposes of this research are to evaluate virtues and strengths included in the new Palestinian textbooks and to assess the acquisitions of these virtues and strengths among the lower elementary students from their teachers' perspectives. The study benefited from the Positive Psychology framework to capture and assess those virtues and strengths either in the new Palestinian textbooks or among the students. To achieve the two previous objectives, two methodologies were utilized, a content analysis and an online survey. In the content analysis method; 82 study textbooks units were selected and analyzed. In the quantitative method, 351 teachers were selected. The results showed that the most frequently mentioned virtues were wisdom and justice, with the least mentioned being temperance and transcendence. The results also revealed that teachers highly assessed the acquisition of virtues and strengths among students. Teachers' demographic factors had impacts on assessing the acquisitions of the virtues and strengths among students. It is concluded that there is a clear imbalance in the distributions of both virtues and strengths. Therefore, the Palestinian school textbooks developers should consider including more of the positive psychology virtues and strengths such as virtues of temperance and transcendence.
\end{abstract}

Keywords Virtues, Strengths, Positive Psychology, Palestinian Textbooks

\section{Introduction}

One of important functions of the school is the promotion of student well-being and meet their mental health needs. One promising framework for doing so, known as whole child education, has emerged from the field of positive psychology [1]. Specifically, whole-child education or positive education emphasizes the promotion of positive mental attributes. Positive psychology and positive education focus on factors that enable children and adolescents to thrive and grow [2].

Peterson and Seligman [3] presented six universal virtues underlying 24-character strengths. The proposed virtues are knowledge, wisdom, courage, justice, humanity, tolerance, and moderation. Schwartz [4] defined character strengths as positive traits reflected in thoughts, feelings, and behaviors. Character strength is a disposition to desire, feel, and act that involves the exercise of judgement and leads to a recognizable human excellence or instance of human flourishing [5]. Character strengths are also a subset of personality traits on which we place moral value [6]. These subsets of personality traits are known as virtues [6].

In the Palestinian case, there is a double value for the curricula. It represents an opportunity for the children to determine their educational destiny and providing them with different kinds of knowledge and skills, and is also 
expected to achieve their mission to change their society in a way that guarantees equality and social justice because of the Palestinian people still living under the Israeli military occupation. Moreover, it might help in achieving economic development and prosperity on the basis of investing all its human potential. This requires focusing on the virtues and moral system and integrating it into the curricula specifically school textbooks.

The Palestinian curriculum aims to enhance understanding, develop sensitivity among students towards their adverse society conditions, help them appreciate and understand their own culture, and develop their self-esteem. In addition, the curriculum helps students learn to respect and understand the concept of humanity in the global environment and prepare to deal with different ideas and situations with a critical and open mind. The curriculum attempts to balance the abilities of students to respect democratic values and defend their rights and at the same time to develop their abilities to use collaborative strategies. In addition, the curriculum aims to enhance the thoughtful and constructive decision-making process in students' personal lives, local communities, and national and global settings [7].

Referring to the virtues, curriculum developers considered love, peace, equality, freedom, human rights, democracy, tolerance, self-esteem, and others, as well as maintaining positive attitudes toward goodness and virtue. These concepts appear in textbooks and supplementary resources. In addition, the curriculum aims to help students analyze, clarify, judge, and acquire the values of civil society in the areas of global, environmental concern, and social responsibility [8].

In general, there are three main approaches to curriculum are the formal, informal, and the hidden curriculum. These approaches should work interchangeably to create an effective one, where teachers can play an important role in conveying the virtues of positive psychology to students [9].

There are several studies that have examined and analyzed virtues of positive psychology in different settings and contexts and recommended that security, self-respect, warm relationships with others, self-fulfillment, sense of accomplishment, being respected, sense of belonging, excitement, and sense of enjoyment as a set of virtues should be included in school textbooks [10-15].

The researchers believe that schools should play a positive role in developing virtues and enhancing them among students as the builders of the future and the pillars of the nation and its hope for liberation, building the country and achieving the sustainable development goals. This desired result can be reached by the virtues of positive psychology in textbooks, which is included in the value system of the Palestinian people, where many previous studies have confirmed the importance of this role $[12,13,14,16]$. Accordingly, the present study aimed to achieve two goals. The first goal was to analyze the content of the new Palestinian school textbooks for the lower primary stage (grades 1 to 4 ) based on a positive psychology framework and the second was to assess the acquisition of virtues and strengths among the lower primary stage students from their teachers' perspectives.

\section{Materials and Methods}

A combination of qualitative and quantitative approaches has been used to answer the research questions; according to Brannen [17], employing mixed methods as a pragmatic approach is used to mitigate weaknesses of any method used.

The used methods were online survey and content analysis instrument. To check the content validity, the instrument was given to ten experts from the psychological and educational fields. The instrument was reviewed after their comments and the final list of strengths were formulated. To ensure the content analysis reliability, the agreement coefficient was calculated between two independent measurements conducted by two researchers who participated in this study which was equal to $=0.84$.

The quantitative approach was used in this study to assess acquisition of virtues and strengths among 1-4 grader from their teachers' perspectives. To achieve this, an online questionnaire was administered as it was difficult to reach intended teachers physically because of the social distancing of COVID-19 pandemic. For the same reason, the researchers used a convenient sample technique, resulted in selecting three hundred and fifty-one teachers out of all teachers from both genders (129 males and 222 females) in the West Bank and Gaza Strip in Palestine.

The questionnaire of the study was designed based on the work of Littman-Ovadia [18], Values in Action Inventory of Strengths [VIA-120]. The inventory is considered as highly positively correlated with satisfaction with life, flourishing, and positive affect and correlated negatively with depression and negative affect [19-21]. This inventory according to Valor, et al. [19], is a comprehensive, measurable and empirically validated inventory of values competences. The questionnaire was adapted to Arab culture using the VIA-120, this was informed by Pan and dae La Puente [22] method in translating and adapting questionnaires, and then the tool's validity was tested.

\subsection{Sampling}

For the quantitative content analysis, the population study was the content of all of the new Palestinian school textbooks for the lower primary stage that include subjects of Arabic language (Our beautiful language), English 
language (English for Palestine), mathematics, national education, science, and Islamic education. Every textbook subject contains two parts (first and second semesters) and the number of textbooks was (48) books containing (226) study units. Eighty-two study units were selected using a stratified random sampling technique to represent all textbooks taught from class I to IV in all subjects.

\subsection{Content Analysis}

The content analysis instrument was derived from the Character Strengths and Virtues (CSV) handbook [3]. In this handbook; the authors attempted to identify and classify the positive psychological traits of human beings. The CSV provided a theoretical framework to assist in understanding strengths and virtues and for developing practical applications for positive psychology. This work identified 6 classes of virtues underlying 24 measurable character strengths [3]. Table 1 shows virtues and strengths based on positive psychology theoretical framework [3,5].

In the quantitative content analysis, the whole textbooks were read in detail by the researchers, during this stage they recorded the frequency of each word that reflecting a specific virtue or strength. Then Words with similar meanings were recorded together. The frequency of the words reflected what kind of virtues and strengths were addressed. The words that were mentioned most often are the words that related to the greatest interest; the virtue or strength word choices were not just driven by content, but also by the underlying virtues or strengths of the contents in the textbooks.

Table 1. Positive psychology virtues and strengths

\begin{tabular}{|c|c|}
\hline Virtues & Strengths \\
\hline \multirow{5}{*}{ Wisdom and Knowledge } & 1. Creativity [originality, ingenuity]. \\
\hline & 2. Curiosity [novelty-seeking, interest, openness to experience]. \\
\hline & 3. Judgment [critical thinking, open-mindedness]. \\
\hline & 4. $\quad$ Perspective [wisdom]. \\
\hline & 5. Love of learning. \\
\hline \multirow{4}{*}{ Courage } & 6. Bravery [valor]. \\
\hline & 7. Persistence: [industriousness, perseverance]. \\
\hline & 8. Integrity: [honesty, authenticity]. \\
\hline & 9. Zest: [enthusiasm, vitality, vigor, energy]. \\
\hline \multirow{3}{*}{ Humanity } & 10. Loves. \\
\hline & 11. Kindness: [nurturance, generosity, care, altruistic love, compassion, "niceness"]. \\
\hline & 12. Social intelligence: [personal intelligence, emotional intelligence]. \\
\hline \multirow{3}{*}{ Justice } & 13. Citizenship: [loyalty, social responsibility, teamwork]. \\
\hline & 14. Fairness. \\
\hline & 15. Leadership. \\
\hline \multirow{4}{*}{ Temperance } & 16. Forgiveness and mercy. \\
\hline & 17. Modesty and humility. \\
\hline & 18. Prudence. \\
\hline & 19. Self-regulation: [self-control]. \\
\hline \multirow{5}{*}{ Transcendence } & 20. Appreciation of beauty and excellence: [wonder, awe, elevation]. \\
\hline & 21. Gratitude. \\
\hline & 22. Hope: [optimism, future orientation, future-mindedness]. \\
\hline & 23. Humor: [playfulness]. \\
\hline & 24. Spirituality: [religiousness, purpose, faith]. \\
\hline
\end{tabular}




\subsection{Online Questionnaire}

The study also aims to assess acquisition of virtues and strengths among the graders 1-4 from their teachers' perspectives. To achieve this goal, the researchers used a quantitative approach by utilizing an online questionnaire due to the COVID-19 pandemic closure. The teachers' population consisted of all grade 1-4 teachers working in the Palestinian public schools in the West Bank. Three hundred and fifty-one teachers were selected using a convenient sample technique. Table 2 provides a detailed demographic information about the teachers.

As shown in table 2, (63\%) of teachers were females. (68.4\%) of teachers teach all subjects except the English language. About (44\%) of them teach in different grades and third of teachers are teaching for more than 16 years. The Majority of teachers (83\%) have positive opinions towards the new Palestinian school textbooks.

The online questionnaire was designed based on the VIA-120 of Littman-Ovadia [20]. Cronbach's alpha coefficients for the 24 subscales of this 120- item version ranged from 0.69 (leadership) to 0.90 (creativity), with a mean of .79. The average correlation between the 24 subscales of the short version and the original version VIA-IS subscales was .93. The VIA-120 highly positively correlated with satisfaction with life, flourishing, and positive affect and correlated negatively with depression and negative affect.

In this study, the researchers adapted the VIA-120 to
Arabic culture and they benefited from recommendations of Pan and Dae La Puente [22] method in translating and adapting questionnaires. They recommended five steps for translating questionnaires' research: prepare, translate and back translate, pretest, revise, and document [22].

The translated (Arabic) questionnaire was reviewed by four experts from the psychological and educational fields and by two specialists in Arabic and English languages working at An-Najah National University [ANNU]. To response on this inventory; the researchers used a five-point Likert scale ranging from 1 (very low) to 5 (very high).

Furthermore, the researchers rephrased the VIA-120 items to be suitable for teachers. For example, in the English version; the first item states "Being able to come up with new and different ideas is one of my strong points" and after rephrasing, it became "My students are able to come up with new and different ideas during teaching them".

To check the adapted Arabic inventory validity of the VIA-120, the corrected item-total correlations were calculated and where a value of $>0.4$ is deemed as acceptable [23]. Based on this value; 114 items remained in the inventory and they significantly positively correlated with their subscales and ranged from (42 to .68). Cronbach's alpha coefficients for the 24 subscales of this adapted Arabic inventory ranged from 0.71 (citizenship) to 0.92 (kindness), with a mean of .83 .

Table 2. Participants Demographic Characteristics

\begin{tabular}{|c|c|c|c|}
\hline \multicolumn{2}{|c|}{ Demographic variables } & \multirow{2}{*}{$\begin{array}{c}\text { Frequency } \\
129\end{array}$} & \multirow{2}{*}{$\begin{array}{c}\text { Percentage } \\
36.8\end{array}$} \\
\hline Condor & Males & & \\
\hline Сениет & Females & 222 & 63.2 \\
\hline \multirow{6}{*}{ Teacher's subject taught } & Mathematics & 19 & 5.4 \\
\hline & Arabic language & 59 & 16.8 \\
\hline & English language & 14 & 4.0 \\
\hline & Islamic Edu. & 8 & 2.3 \\
\hline & Science & 11 & 3.1 \\
\hline & All subjects except English & 240 & 68.4 \\
\hline \multirow{5}{*}{ Teacher's grade taught } & First grade & 50 & 14.2 \\
\hline & Second grade & 48 & 13.7 \\
\hline & Third grade & 24 & 6.8 \\
\hline & Fourth grade & 75 & 21.4 \\
\hline & $>$ one grade & 154 & 43.9 \\
\hline \multirow{4}{*}{$\begin{array}{l}\text { Teacher's years of } \\
\text { Teaching }\end{array}$} & $<5$ years & 104 & 29.6 \\
\hline & 5-10 years & 57 & 16.2 \\
\hline & $11-16$ years & 70 & 19.9 \\
\hline & $>16$ years & 120 & 34.2 \\
\hline \multirow{2}{*}{$\begin{array}{l}\text { Teachers' opinions } \\
\text { textbooks }\end{array}$} & Positive & 291 & 82.9 \\
\hline & Negative & 60 & 17.1 \\
\hline
\end{tabular}


Table 3. The total word frequencies related to positive psychology virtues and strengths as mentioned in the new textbooks for the lower primary stage ( $\mathrm{n}=226$ units).

\begin{tabular}{|c|c|c|}
\hline Strengths & Frequency & Percentage \\
\hline Creativity & 818 & 8.62 \\
\hline Curiosity & 352 & 3.71 \\
\hline Judgment & 1104 & 11.63 \\
\hline Perspective & 111 & 1.17 \\
\hline Love of learning & 1043 & 10.98 \\
\hline Bravery & 274 & 2.89 \\
\hline Persistence & 209 & 2.20 \\
\hline Integrity & 678 & 7.14 \\
\hline Zest & 309 & 3.25 \\
\hline Loves & 596 & 6.28 \\
\hline Kindness & 720 & 7.58 \\
\hline Social intelligence & 225 & 2.37 \\
\hline Citizenship & 1284 & 13.52 \\
\hline Fairness & 193 & 2.03 \\
\hline Leadership & 119 & 1.25 \\
\hline Forgiveness and mercy & 34 & 0.36 \\
\hline Modesty and humility & 47 & 0.49 \\
\hline Prudence & 57 & 0.60 \\
\hline Self-regulation & 69 & 0.73 \\
\hline Appreciation of beauty and excellence & 616 & 6.49 \\
\hline Gratitude & 17 & 0.18 \\
\hline Hope & 30 & 0.32 \\
\hline Humor & 200 & 2.11 \\
\hline Spirituality & 390 & 4.11 \\
\hline Total & 9495 & 100.00 \\
\hline Wisdom and Knowledge & 3423 & 36.05 \\
\hline Courage & 1470 & 15.48 \\
\hline Humanity & 1541 & 16.23 \\
\hline Justice & 1596 & 16.81 \\
\hline Temperance & 212 & 2.23 \\
\hline Transcendence & 1253 & 13.20 \\
\hline Total & 9495 & 100 \\
\hline
\end{tabular}

\section{Findings}

\subsection{Findings of Content Analysis of Textbooks}

Based on the quantitative content analysis, table 3 shows the total frequencies of words used related to virtues and strengths as mentioned in the new textbooks for grades 1 to 4 . The results show that the most six frequently used words related to strengths mentioned in the new textbooks are Citizenship (13.52\%), Judgement (11.63\%), Love of learning (10.98\%), Creativity (8.62\%), Kindness (7.58\%), and Integrity (7.14\%). On the other hand, the results show that relatively the lowest six frequently used words related to strengths mentioned in the new textbooks are gratitude $(0.18 \%)$, hope $(0.32 \%)$, forgiveness and mercy $(0.36 \%)$, modesty and humility $(0.49 \%)$, prudence $(0.60 \%)$, and self-regulation $(0.73 \%)$.

In term of virtues, the results show that the most two frequently used words related to virtues mentioned in the new textbooks are Wisdom and knowledge (36.05\%) and Justice (16.81\%). Whilst, the results show that relatively the lowest two frequently used words related to virtues mentioned in the new Palestinian school textbooks are temperance (2.23\%) and transcendence (13.20\%).

In order to discover the effects of subjects (Arabic language, English language, mathematics, national education, science, and Islamic education), grades (class I to IV), and the interaction between subjects and grades on the availability of the six virtues in the textbooks, a three-way MANOVA was used. To use MANOVA, there is an assumption of multivariate normality which can be tested by Shapiro-Wilk test of normality and the analysis indicated that all dependent variables (the six virtues) are normally distributed as the significant value is greater than 0.05 .

To use MANOVA, the multiple dependent variables 
should be correlated to each other at a low to moderate level [24]. The analysis indicated a moderate strength of association among all the six virtues. Hence, the assumption of MANOVA is met as there is no multi-collinearity. The multivariate homogeneity of covariance matrices tested with Box's $M$ test revealed that the $\mathrm{M}$ value of 4.61 was insignificant $(\mathrm{p}=0.63)$. Therefore, the assumption of homogeneity of covariance matrices was satisfied. Table 4 shows three-way MANOVA results for the effects of subjects and grades on virtues.

Table 4 shows the results of three-way MANOVA for positive psychology virtues differences according to subjects and grades as independent variables. The MANOVA revealed insignificant multivariate effects for subjects, Wilks' lambda $=0.041, \mathrm{~F}=2.206, \mathrm{p}>0.05$, for grades, Wilks' lambda $=0.74, \mathrm{~F}=0.878, \mathrm{p}>0.05$, and for interaction between subjects and grades, Wilks' lambda $=$ $0.50, \mathrm{~F}=2.473, \mathrm{p}>0.05$.
Table 4. Results of three-way MANOVA of the effects of subjects, grades, and interaction on availability of the positive psychology virtues in the new Palestinian school textbooks.

\begin{tabular}{|c|c|c|c|}
\hline $\begin{array}{c}\text { Independent } \\
\text { Variables }\end{array}$ & $\begin{array}{c}\text { Wilks' } \\
\text { Lambda }\end{array}$ & F-value & P-value \\
\hline Subjects & 0.499 & 2.511 & 0.069 \\
\hline Grades & 0.740 & 0.878 & 0.534 \\
\hline SubjectsXGrades & 0.503 & 2.473 & 0.073 \\
\hline
\end{tabular}

\subsection{Findings of Online Questionnaire}

To assess the acquisition of virtues and strengths from their teachers' perspectives, the researchers compared each score on every virtues and strengths with an appropriate cut point value, based on the mid-point between the minimum and the maximum values (hypothetical mean = 3). And to test the differences between each score and its cut point value, the researchers used one sample t-test. Table 5 shows results.

Table 5. Descriptive statistics of virtues and strengths among 1-4 graders from their teachers' perspectives and the results of one sample t-test $(\mathrm{n}=351)$.

\begin{tabular}{|c|c|c|c|c|}
\hline Strengths & Mean & Sd. & t-value & P-value \\
\hline Creativity & 3.20 & 0.89 & $4.27 * *$ & 0.000 \\
\hline Judgment & 3.11 & 0.81 & $2.44^{*}$ & 0.015 \\
\hline Perspective & 3.29 & 1.03 & $5.28 * *$ & 0.000 \\
\hline Love of learning & 3.31 & 0.86 & $6.70^{* *}$ & 0.000 \\
\hline Bravery & 3.45 & 0.76 & $11.14^{* *}$ & 0.000 \\
\hline Persistence & 3.52 & 0.79 & $12.40 * *$ & 0.000 \\
\hline Integrity & 3.38 & 0.76 & $9.24 * *$ & 0.000 \\
\hline Loves & 3.63 & 0.69 & $17.09 * *$ & 0.000 \\
\hline Kindness & 3.53 & 0.70 & $14.10^{* *}$ & 0.000 \\
\hline Social intelligence & 3.61 & 0.73 & $15.69 * *$ & 0.000 \\
\hline Citizenship & 3.51 & 0.71 & $13.55^{* *}$ & 0.000 \\
\hline Fairness & 3.45 & 0.69 & $12.15^{* *}$ & 0.000 \\
\hline Leadership & 3.49 & 0.97 & $9.51^{* *}$ & 0.000 \\
\hline Forgiveness and mercy & 3.59 & 0.82 & $13.77 * *$ & 0.000 \\
\hline Modesty and humility & 3.46 & 0.92 & $9.50 * *$ & 0.000 \\
\hline Self-regulation & 3.27 & 0.94 & $5.36^{* *}$ & 0.000 \\
\hline Appreciation of beauty and excellence & 3.45 & 0.79 & $10.76^{* *}$ & 0.000 \\
\hline Gratitude & 3.43 & 1.00 & $7.98^{* *}$ & 0.000 \\
\hline Hope & 3.42 & 0.88 & $8.82^{* *}$ & 0.000 \\
\hline Humor & 3.59 & 0.80 & $13.92^{* *}$ & 0.000 \\
\hline Spirituality & 3.60 & 0.71 & $16.02 * *$ & 0.000 \\
\hline Curiosity & 3.15 & 0.82 & $3.54 * *$ & 0.000 \\
\hline Zest & 3.62 & 0.89 & $12.98 * *$ & 0.000 \\
\hline Prudence & 3.20 & 0.86 & $4.30 * *$ & 0.000 \\
\hline Wisdom and knowledge & 3.21 & 0.81 & $4.90^{* *}$ & 0.000 \\
\hline Courage & 4.38 & 0.91 & $28.35^{* *}$ & 0.000 \\
\hline Humanity & 3.59 & 0.69 & $16.13^{* *}$ & 0.000 \\
\hline Justice & 3.48 & 0.73 & $12.43^{* *}$ & 0.000 \\
\hline Temperance & 3.38 & 0.77 & $9.22 * *$ & 0.000 \\
\hline Transcendence & 3.50 & 0.72 & $13.04 * *$ & 0.000 \\
\hline Total & 3.46 & 0.70 & $12.23^{* *}$ & 0.000 \\
\hline
\end{tabular}


As the results indicate, the levels of all virtues and strengths are significantly higher than the critical value or the hypothetical mean of 3 where the mean of total score was $(3.46 \pm 0.70, \mathrm{t}(350)=12.23, \mathrm{p}<.001)$. The results show that the highest six means are for strengths of loves $(3.63 \pm 0.69, \mathrm{t}(350)=17.09, \mathrm{p}<.001)$, spirituality $(3.60 \pm$ $0.71, \mathrm{t}(350)=16.02, \mathrm{p}<.001)$, social intelligence $(3.61 \pm$ 0.73, $\mathrm{t}(350)=15.69, \mathrm{p}<.001)$, kindness $(3.53 \pm 0.70$, $\mathrm{t}(350)=14.10, \mathrm{p}<.001)$, humor $(3.59 \pm 0.80, \mathrm{t}(350)=$ 13.92, $\mathrm{p}<.001)$, and forgiveness and mercy (3.59 \pm 0.82 , $t(350)=13.77, p<.001)$. On the other hand, relatively the lowest six strengths are for the strengths of judgement $(3.11 \pm 0.81, \mathrm{t}(350)=2.44, \mathrm{p}<.05)$, curiosity $(3.15 \pm 0.82$, $\mathrm{t}(350)=3.45, \mathrm{p}<.001)$, creativity $(3.20 \pm 0.89, \mathrm{t}(350)=$ 4.27, $\mathrm{p}<.001)$, prudence $(3.20 \pm 0.86, \mathrm{t}(350)=4.30, \mathrm{p}$ $<.001)$, perspective $(3.29 \pm 1.03, \mathrm{t}(350)=5.28, \mathrm{p}<.001)$, and self-regulation $(3.27 \pm 0.94, \mathrm{t}(350)=5.36, \mathrm{p}<.001)$.

In term of virtues, the results show that the highest two means were for courage virtue $(4.38 \pm 0.91, \mathrm{t}(350)=$ 28.35, $\mathrm{p}<.001)$ followed by the humanity $(3.59 \pm 0.69$, $\mathrm{t}(350)=16.13, \mathrm{p}<.001)$. Whilst, the two lowest means were for wisdom and knowledge virtue (3.21 \pm 0.81 , $\mathrm{t}(350)$ $=4.90, \mathrm{p}<.001)$ followed by the temperance $(3.38 \pm 0.77$, $\mathrm{t}(350)=9.22, \mathrm{p}<.001)$.

In order to determine the differences among teachers' perceptions on acquisition of virtues among their students according to teachers' demographic factors: (a) gender, (b) teacher's subject taught, (c) teacher's grade taught, (d) teacher's years of teaching, and (e) teachers' opinion about the new Palestinian school textbooks; MANOVA procedures were used. Shapiro-Wilk test of normality was used and the analysis indicated that all dependent variables (the six virtues) are normally distributed as the significant value is greater than 0.05 . To use MANOVA, the multiple dependent variables should be related with each other at a low to moderate level [24]. The analysis indicated a moderate strength of association among all the six virtues. Hence, the assumption of MANOVA is met as there is no multi-collinearity. The multivariate homogeneity of covariance matrices tested with Box's M test revealed that the $M$ value of 5.82 was insignificant ( $p$ $=0.84$ ). Therefore, the assumption of homogeneity of covariance matrices was satisfied. Table 6 shows five-way MANOVA results for the effects of teachers' demographic factors on their perceptions on the acquisition of virtues among their students.

Table 6. Results of five-way MANOVA of the effects of teachers' demographic factors on their perceptions on the acquisition of virtues among their students $(\mathrm{n}=351)$.

\begin{tabular}{|c|c|c|c|}
\hline $\begin{array}{c}\text { Independent } \\
\text { Variables }\end{array}$ & $\begin{array}{c}\text { Wilks' } \\
\text { Lambda }\end{array}$ & F-value & P-value \\
\hline Gender & 0.87 & $8.25^{* *}$ & 0.000 \\
\hline $\begin{array}{c}\text { Teacher's subject } \\
\text { taught }\end{array}$ & 0.84 & $1.94^{* *}$ & 0.002 \\
\hline $\begin{array}{c}\text { Teacher's grade } \\
\text { taught }\end{array}$ & 0.82 & $2.88^{* *}$ & 0.000 \\
\hline $\begin{array}{c}\text { Teacher's years of } \\
\text { teaching }\end{array}$ & 0.76 & $5.15^{* *}$ & 0.000 \\
\hline $\begin{array}{c}\text { Teachers' opinion } \\
\text { about the new } \\
\text { Palestinian school } \\
\text { textbooks }\end{array}$ & 0.67 & $26.87^{* *}$ & 0.000 \\
\hline
\end{tabular}

Table 6 shows the MANOVA revealed significant multivariate effects for teacher gender, Wilks' lambda = $0.87, \mathrm{~F}=8.25, \mathrm{p}<0.001$, for teacher's subject taught, Wilks' lambda $=0.84, \mathrm{~F}=1.94, \mathrm{p}<0.01$, for teacher's grade taught, Wilks' lambda $=0.82, \mathrm{~F}=2.88, \mathrm{p}<0.001$, for teacher's years of teaching, Wilks' lambda $=0.76, \mathrm{~F}=$ 5.15, $\mathrm{p}<0.001$, and for teachers' opinion about the new Palestinian school textbooks Wilks' lambda $=0.67, \mathrm{~F}=$ 26.87, $\mathrm{p}<0.001$. The five-way MANOVA results are summarized on table 7 .

Table 7. Summary of MANOVA results.

\begin{tabular}{|c|c|c|c|c|c|c|c|c|c|c|}
\hline \multirow{2}{*}{ The variable } & \multicolumn{2}{|c|}{ Gender } & \multicolumn{2}{c|}{ Subject } & \multicolumn{2}{c|}{ Grade } & \multicolumn{2}{c|}{ Years of teaching } & \multicolumn{2}{c|}{ Opinion } \\
\cline { 2 - 11 } & $\mathrm{F}$ & $\mathrm{P}$ & $\mathrm{F}$ & $\mathrm{P}$ & $\mathrm{F}$ & $\mathrm{P}$ & $\mathrm{F}$ & $\mathrm{P}$ & $\mathrm{F}$ & $\mathrm{P}$ \\
\hline Wisdom and knowledge & $7.03^{* *}$ & 0.008 & $2.83^{*}$ & 0.016 & 1.93 & 0.105 & 2.13 & 0.097 & $72.69^{* *}$ & 0.000 \\
\hline Courage & 0.13 & 0.715 & 1.76 & 0.121 & $3.27^{*}$ & 0.012 & 1.94 & 0.124 & $107.72^{* *}$ & 0.000 \\
\hline Humanity & 3.80 & 0.052 & $2.55^{*}$ & 0.028 & $3.39^{*}$ & 0.010 & 2.18 & 0.090 & $147.18^{* *}$ & 0.000 \\
\hline Justice & 2.85 & 0.092 & 1.68 & 0.140 & $3.51^{* *}$ & 0.008 & 2.15 & 0.094 & $116.12^{* *}$ & 0.000 \\
\hline Temperance & 1.51 & 0.220 & $2.45^{*}$ & 0.033 & $3.39^{*}$ & 0.010 & $4.22^{* *}$ & 0.006 & $81.16^{* *}$ & 0.000 \\
\hline Transcendence & 2.56 & 0.111 & 1.98 & 0.081 & $3.57^{* *}$ & 0.007 & $3.42^{*}$ & 0.017 & $119.74^{* *}$ & 0.000 \\
\hline
\end{tabular}


The detailed results of the main effects of each independent variable on dependent variables are as follows. Regarding gender, there was a statistically significant difference between males and females on students acquisition of wisdom and knowledge virtue [F(1, $349)=7.03, \mathrm{p}<0.01]$. Mean scores and SD values with regard to wisdom and knowledge were calculated and the results indicated that female teachers $(3.27 \pm 0.78)$ more than male teachers $(3.11 \pm 0.86)$ tended to assess the virtue of wisdom and knowledge acquisition among students.

In relation to teachers' subjects taught, there were statistically significant differences in students' acquisition of wisdom and knowledge $[\mathrm{F}(5,345)=2.83$, $\mathrm{p}<0.05]$, humanity $[\mathrm{F}(5,345)=2.55, \mathrm{p}<0.05]$, and temperance $[F(5,345)=2.45, \mathrm{p}<0.05]$ due to subjects that teachers teach. Post Hoc tests were performed for all the three dependent variables (wisdom and knowledge, humanity, and temperance). Results revealed that those teaches who teaching the Arabic language tended to assess the acquisition of wisdom and knowledge, humanity, and temperance among students more than teachers who teach other subjects did. Regarding teachers' grades taught, there were statistically significant differences in students' acquisition of courage $[\mathrm{F}(4,346)=3.27, \mathrm{p}<0.05]$, humanity $[\mathrm{F}(4,346)=3.39, \mathrm{p}<0.05]$, justice $[\mathrm{F}(4,346)=$ 3.51, $\mathrm{p}<0.01]$, temperance $[\mathrm{F}(4,346)=3.39$, $\mathrm{p}<0.05]$, and transcendence $[\mathrm{F}(4,346)=3.57, \mathrm{p}<0.01]$ due to grades that teachers teach. Post Hoc tests were performed for all the five dependent variables (courage, humanity, justice, temperance, and transcendence). Results revealed that those teaches who teaching the fourth grade tended to assess the acquisition of courage, humanity, justice, temperance, and transcendence among students more than teachers who teach other grades did.

In relation to years of teaching, there were statistically significant differences in students' acquisition of temperance $[\mathrm{F}(3,347)=4.22, \mathrm{p}<0.001]$ and transcendence $[\mathrm{F}(3,347)=3.42, \mathrm{p}<0.05]$ due to years of teaching. Post Hoc tests were performed for all the two dependent variables (temperance and transcendence). Results revealed that those teachers with more than 16 years' experience tended to assess the acquisition of temperance and transcendence among students more than teachers who teach for less than 16 years.

Regarding teachers' opinion about the new textbooks, there was a statistically significant difference between positive and negative opinions on students acquisition of all virtues, wisdom and knowledge $[\mathrm{F}(1,349)=72.69$, $\mathrm{p}<$ $0.001]$, courage $[\mathrm{F}(1,349)=107.72, \mathrm{p}<0.001]$, humanity $[\mathrm{F}(1,349)=147.18, \mathrm{p}<0.001]$, justice $[\mathrm{F}(1,349)=$ 116.12, $\mathrm{p}<0.001]$, temperance $[\mathrm{F}(1,349)=81.16$, $\mathrm{p}<$ $0.001]$, and transcendence $[\mathrm{F}(1,349)=119.74, \mathrm{p}<0.001]$. Results revealed that those teaches who had positive opinion about the new textbooks tended to assess the acquisition of all six virtues among students more than teachers who had negative opinion did.

\section{Discussion and Conclusion}

Considering the first question of the study, the results revealed that the most six strengths mentioned in the textbooks are citizenship, judgement, love of learning, creativity, kindness, and integrity. On the other hand, relatively the lowest six strengths -comparing with the above results- are gratitude, hope, forgiveness and mercy, modesty and humility, prudence, and self-regulation. In terms of virtues, the results revealed that the most two virtues are wisdom and knowledge and justice. Whilst, relatively the lowest two virtues mentioned are temperance and transcendence.

In the content analysis results; the most prominent strengths and virtues that in the new textbooks are the virtues of wisdom and knowledge (especially judgement, love of learning, and creativity) and justice (especially citizenship). Furthermore, the other prevalent virtues in the textbooks are humanity (kindness) and integrity (courage). Whilst, relatively the lowest prevalent strengths and virtues are the virtues of transcendence (especially gratitude and hope) and temperance (especially forgiveness and mercy, modesty and humility, prudence, and self-regulation). Accordingly, these results revealed an imbalance in the distributions of each of the six virtues and their strengths.

The researchers justified the results based on the Palestinian context, situations, and culture. Although the Palestinian education system interested in students' academic achievement, developer of the textbooks was aware of values and virtues that should be included in these textbooks. This in turn encourages students to be motivated, feel respected and valued, and providing them with educational and psychological values and virtues to prepare them to be good citizens in their future lives.

The new textbooks tried to be balanced and wise through interest in academic achievement and the emotionally, intellectually, and socially growth of the whole students by instilling positive psychology virtues and strengths values that included clearly in the textbooks. It is obvious that developers of the textbooks believe that students are the agencies of social, political, and educational reform, thus they reflected this awareness through preparing textbooks full of educational values.

The new textbooks focus on the virtue of wisdom and knowledge since it emphasizes cognitive strengths that entail the acquisition and use of knowledge to push the learner to be more creative, critical, curious, open-minded, learning lover, and perspective. These strengths include positive traits related to the acquisition and use of information in the service of the good life [3]. Since knowledge is power for Palestinian people who live under Israeli occupation and wish to establish their independent 
state, therefore one of the tools to get rid of the Israeli occupation is knowledge and wisdom which foster students to be more aware of their social, economic, and political life.

Most of the Palestinian students are Muslims, so the educational system and designers of the school textbooks derive many values from the Islamic heritage and the Arabic traditions which prompt the importance and necessity of knowledge and education. Developer of the textbooks tried to create a new version of textbooks that is in line with modernity and the twelve 21st century skills which focus on critical and creative thinking, and information literacy. Therefore, knowledge and wisdom play vital roles in preparing the new generation cognitively.

In relation to the virtue of justice, it focuses on strengths that underlie healthy community life such as citizenship, social responsibility, loyalty, teamwork, fairness, and leadership [3] Therefore, the Palestinian textbook provides students with values of respect for life and problem solving effectively without the use of physical force and attacking others and by enforcing and respecting the law.

In fact, one of the Palestinian dreams is establishing democratic state that encourages principles of justice including equality, equity, upholding human rights, and denial of discrimination and oppression. These virtues and strengths come in line with the values of suffering people who live under occupation for 72 years and as an opposite reaction against social and political injustice. Therefore, textbooks might try to encourage a culture of nonviolent resistance among students. Accordingly, the new textbooks tried to pay attention to establishing and enhancing senses of citizenship and patriotism among students as a part of social responsibility and loyalty and they tried to increase a sense of obligations to family, society, motherland, heritage, traditions, and customs.

The other common virtues found in the textbook are humanity and courage. Humanity related to interpersonal strengths that involve tending and befriending others including kindness, generosity, nurturance, care, compassion, altruistic love, and niceness, on the other hand, courage is emotional strengths that involve the exercise of will to accomplish goals in the face of opposition, external or internal including integrity [3]. In fact, virtues of humanity and courage are prominent in Arabic and Islamic traditions and heritage, thus thousands of stories and verses that emphasize these virtues could be found. Islamic and Arabic culture is a collectivistic one which in turn focuses on kindness in terms of generosity, caring others, compassion, altruistic love, niceness. For example, in the Holy Quran 'Serve God, and join not any partners with Him; and do good -- to parents, kinsfolk, orphans, those in need, neighbors who are near, neighbors who are strangers, the companion by your side, the wayfarer (you meet), and what your right hands possess: for God loves not the arrogant, the vainglorious [25].

In encouraging values of integrity, authenticity, and honesty, Prophet Muhammad said: 'You must be truthful. Verily, truthfulness leads to righteousness and righteousness leads to Paradise. A man continues to be truthful and encourages honesty until he is recorded with Allah as truthful. And beware of falsehood. Verily, falsehood leads to wickedness and wickedness leads to the Hellfire. A man continues tell lies and encourages falsehood until he is recorded with Allah as a liar' [26].

Students in the middle childhood stage which include children of six to twelve years of age [27] are still in a developmental process. Because cognitive and emotional maturity increase with experiences and age students in middle childhood cannot regulate their emotions and behaviors effectively, and their intellectual abilities limit them to construct meaning and absorb virtues specifically those which require abstract and inferential thinking such as virtues of knowledge and wisdom and temperance $[28,29]$. Relatively, scores on both courage and humanity virtues showed a slight upward trend compared to scores on knowledge and temperance since virtues of courage and humanity might be modelled easily through social interactions and relationships. While virtues of knowledge and temperance require more intellectual and moral abilities [30].

More female teachers than male teachers tended to assess the virtue of wisdom and knowledge acquisition among students and this result consistent with several studies has examined and reported gender differences in character strengths [31-33] in favor to females. A possible reason behind that, female teachers who work in elementary schools are more motivated and effective than male teachers, female teachers are more nurturing, and that male teachers are more laid back, and male teachers are more dominant and commanding with students. Male teachers get too bored or lose interest in teaching at elementary schools which affects their performance negatively. Accordingly, male teachers pay less attention to instilling strengths of knowledge and wisdom virtue among their students [34,35].

In addition, the study revealed a statistically significant difference between positive and negative opinions on students' acquisition of all virtues. Whereas, those teachers who had a positive opinion about the new textbooks tended to assess the acquisition of all virtues among students more than teachers who had a negative one. This result seems logical because teachers who had positive opinions are able to recognize virtues in the textbooks and that lead them to plan how to acquire virtues for students.

The study revealed statistically significant differences in students' acquisition of wisdom and knowledge, humanity and temperance due to subjects that teachers teach. Those teachers who teaching the Arabic language tended to assess the acquisition of wisdom and knowledge, 
humanity, and temperance among students more than teachers who teach other subjects. This result seems logical, since Arabic language textbooks are full of texts and stories which include values and virtues comparing with other subjects. Furthermore, the results showed statistically significant differences in students' acquisition of courage, humanity, justice, temperance, and transcendence due to grades that teachers teach. Those teaches who teaching the fourth grade tended to assess the acquisition of the above-mentioned virtues among students more than teachers who teach other grades. Might the reason behind this result that students in the fourth grade are able to understand and realize those virtues due to their age development [28,29].

Moreover, the study showed statistically significant differences in students' acquisition of temperance and transcendence due to years of teaching. Results revealed that those teachers with 16 years' experience tended to assess the acquisition of temperance and transcendence among students more than teachers with less experience. Expert teachers have more knowledge of how to teach and instill virtues among students specifically those which required patience. Expert teachers have high competencies to determine the most effective ways to teach and promote higher-order thinking conducive to raise students' awareness of themselves by promoting reflective thinking which in turn leads them to possess advanced virtues like temperance and transcendence.

To conclude, the textbooks enhanced virtues and strengths that are necessary for students' development emotionally, intellectually, and socially. These virtues and strengths have strong roots in Arabic and Islamic heritage and at the same time, coming in line with modernity and the twelve 21st century skills. Furthermore, these virtues and strengths are consistent with positive psychology theory Even though some virtues and strengths still need to be included such as transcendence (especially gratitude and hope) and temperance (especially forgiveness and mercy, modesty and humility, prudence, and self-regulation).

\section{Limitations and Recommendations}

The study aimed at investigating the acquisition of Positive Psychology Virtues by students from the perception of their teachers; the blockade leads to a decreased contribution from the Gaza strip teachers and East Jerusalem.

Based on the findings, the present study recommended the following: (a) The Palestinian school textbooks developers should consider including more of the positive psychology virtues and strengths such as virtues of temperance and transcendence and strengths of gratitude, hope, forgiveness and mercy, modesty and humility, prudence, and self-regulation. (b) Teachers should be paid more attention to enhance the strengths of judgement, curiosity, creativity, prudence, perspective, and self-regulation among their students. (c) Further studies should be conducted on different school grades such as upper primary and secondary schooling. (d) Feminization of primary education should be taken into consideration and followed. (e) Carrying out training programs for in and pre-service teachers to be able to impart and enhance virtues and strengths among students.

\section{Acknowledgements}

This work was supported by the deanship of scientific research at An-Najah National University under the second projects' call in 2018.

\section{REFERENCES}

[1] J. Norrish, P. Williams, M. O'Connor, J. Robinson. An applied framework for positive education. International Journal of Wellbeing, 3(2), 2013.

[2] C. Peterson, M.E. Seligman. Character Strengths and Virtues: A Handbook and Classification (New York: American Psychological Association \& Oxford University Press, 2004). Reflective Practice: Formation and Supervision in Ministry, 32. 2012.

[3] J. Wagner, F. Gander, R. T. Prover, W. Ruch. Character strengths and PERMA: Investigating the relationships of character strengths with a multidimensional framework of well-being. Applied Research in Quality of Life, 15(2), 307-328. 2020.

[4] S. Schwartz, K. Boehnke. Evaluating the structure of human values with confirmatory factor analysis. Journal of research in personality, 38(3), 230-255, 2004.

[5] N. Park, C. Peterson, M. Seligman. Strengths of character and well-being. Journal of social and Clinical Psychology, 23(5), 603-619, 2004.

[6] W. Xie. An investigation of virtues (derived from character strengths) in relation to psychological adjustment among Chinese international college students. 2015.

[7] J. Bron, W. Veugelers. Why we need to involve our students in curriculum design: Five arguments for student voice. Curriculum and teaching dialogue, 16(1/2), 125, 2014.

[8] F. Moughrabi. The politics of Palestinian textbooks. Journal of Palestine Studies, 31(1), 5-19, 2001.

[9] P. Tomlinson, M. Quinton, M. (Eds.). Values across the curriculum. Routledge. 2019.

[10] G. Rich. Teaching tools for positive psychology: A comparison of available textbooks. The Journal of Positive Psychology, 6(6), 492-498, 2011.

[11] K. Karatekin, Z. Merey, O. Sönmez, Z. Kuş. Social studies candidate teachers' attitudes towards human rights education. Electronic Turkish Studies, 7(4), 2012. 
[12] B. Dilmaç, A. Kulaksizoğlu, H, Ekșl1. An Examination of the Humane Values Education Program on a Group of Science High School Students. Educational Sciences: Theory \& Practice, 7(3), 2007.

[13] M. Sari, A. Doganay. Hidden Curriculum on Gaining the Value of Respect for Human Dignity: A Qualitative Study in Two Elementary Schools in Adana. Educational Sciences: Theory and Practice, 9(2), 925-940, 2009.

[14] M. Veisson. Values of Estonian Students, Teachers and Parents. Online Submission. A Case Study of the North Star Intermediate Textbook Educational aims and objectives. 2009.

[15] R. Germain. Values Education Influence on Elementary Students' Self-Esteem (Unpublished doctoral dissertation). San Diego University. 2001.

[16] T. Lovat, R. Toomey. Values education and quality teaching. Springer. 2009.

[17] J. Brannen, J. (Ed.). Mixing methods: Qualitative and quantitative research. Routledge. 2017.

[18] H. Littman-Ovadia. Brief report: short form of the VIA inventory of strengths-construction and initial tests of reliability and validity. International Journal of Humanities Social Sciences and Education, 2(4), 229-237, 2015.

[19] C. Valour, P. Antonetti, A. Merino. The relationship between moral competences and sustainable consumption among higher education students. Journal of Cleaner Production, 119-161, 2020.

[20] R. Kumar, Bakhshi, D. Singh. Exploring the Role of Character Strengths in Positive Mental Health of College Students. Studies in Indian Place Names, 40(3), 2522-2533, 2015.

[21] X. Zeng, Y. Sun, Y. Deng, T. Oei. Appreciative joy rooted in Chinese culture: Its relationship with strengths in values in action. The Journal of Positive Psychology, 15(1), 112-121, 2020.

[22] Y. Pan, M. de La Puente. Census Bureau guideline for the translation of data collection instruments and supporting materials: Documentation on how the guideline was developed. Survey Methodology, 6. 2005.
[23] A. Field. Discovering statistics using IBM SPSS statistics. sage. 2013

[24] N. Leech, K. Barrett, G. Morgan. SPSS for intermediate statistics: Use and interpretation. Psychology Press. 2015.

[25] Quran, Chapter 4 The Women [An-Nisa], Verse 36.

[26] I. Bukhari. Sahih al-Bukhari. Kitab Diyat, (45). 1981.

[27] L. Pulkkinen. Human development from middle childhood to middle adulthood: Growing up to be middle-aged. Psychology Press. 2017.

[28] M. Ferragut, M. Blanca, M. Ortiz-Tallo. Psychological virtues during adolescence: A longitudinal study of gender differences. European Journal of Developmental Psychology, 11(5), 521-531, 2014.

[29] M. Linkins, R. Niemiec, J. Gillham, D. Mayerson. Through the lens of strength: A framework for educating the heart. The Journal of Positive Psychology, 10(1), 64-68. 2015.

[30] S. Bosacki. Social cognition in middle childhood and adolescence: Integrating the personal, social, and educational lives of young people. John Wiley \& Sons. 2016.

[31] R. Biswas-Diener. From the equator to the North Pole: A study of character strengths. Journal of Happiness Studies, 7(3), 293-310, 2006.

[32] P. Linley, J. Maltby, A. Wood, S. Joseph, S. Harrington, C. Peterson, M. Seligman. Character strengths in the United Kingdom: The VIA inventory of strengths. Personality and individual differences, 43(2), 341-351, 2007.

[33] S. Shimai, K. Otake, N. Park, C. Peterson, M. Seligman Convergence of character strengths in American and Japanese young adults. Journal of Happiness Studies, 7(3), 311, 2006.

[34] K. Muralidharan, K. Sheth. Bridging education gender gaps in developing countries: The role of female teachers. Journal of Human Resources, 51(2), 269-297, 2016.

[35] T. Wood. Teacher Perceptions of Gender-Based Differences among Elementary School Teachers. International Electronic Journal of Elementary Education, 4(2), 317-345, 2012. 